\title{
A HELENA ÉPICA SOB A ÓTICA DO GÊNERO
}

Fábio de Souza Lessa ${ }^{1}$

Felipe Marques Maciel $^{2}$

\begin{abstract}
Resumo: A proposta deste artigo é analisar a personagem Helena na Ilíada e na Odisseia a partir do conceito de gênero. Para isso, elegemos quatro eixos de investigação - técnico-poético, espacial, ético e discursivo - para ver de que maneira, e com quais possíveis intenções, Helena subverte as relações de gênero vigentes na épica homérica. Defendemos que a análise das falas e ações da personagem revela que o poeta confere a ela um status privilegiado, o que nos faz refletir sobre quais os âmbitos de ação e participação das mulheres à época de Homero.

Palavras-chave: Grécia Arcaica, Homero, Helena, Gênero.
\end{abstract}

Helena, a Argiva, em prol da qual muitos dos aqueus morreram em Troia, longe da amada terra pátria. (HOMERO, Ilíada, II, vv. 162-163)³.

\section{INTRODUÇÃo}

Os versos de Homero que constituem a epígrafe de nosso texto já indicam que Helena, a mulher mais bela dentre os helenos, possui papel preponderante nos conflitos entre gregos e troianos. A espartana é vista pelo poeta como a causadora da morte de muitos homens, de ambos os lados. Os comentários feitos pelos ancióes de Troia quanto à chegada de Helena à muralha (Ilíada, III, vv. 156-157) atestam uma visão idêntica àquela tida pelos próprios gregos sobre Helena. É ainda responsável pela dor de pais, mães,

1 Professor Associado de História Antiga do Instituto de História (IH) e dos Programas de PósGraduação em História Comparada (PPGHC) e de Letras Clássicas (PPGLC) da Universidade Federal do Rio de Janeiro (UFRJ). Membro do Laboratório de História Antiga (LHIA) / UFRJ e Membro Colaborador do Centro de Estudos Clássicos e Humanísticos da Universidade de Coimbra.E-mail: fslessa@uol.com.br

2 Mestrando do Programa de Pós-Graduação em Letras Clássicas na Faculdade de Letras da Universidade Federal do Rio de Janeiro. Membro do Laboratório de História Antiga (LHIA) / UFRJ. Bolsista CAPES. Email: fmarquesmaciel@gmail.com.

3 Todas as citações da Ilíada e da Odisseia foram traduzidas por Frederico Lourenço (2013 e 2011). 
filhos, esposas e maridos. Tal constatação permite a Claude Calame (2000, p. 146) afirmar que "os protagonistas da Ilíada não deixam de se referir à Helena como a causadora dos seus males". ${ }^{4}$

No período clássico tal situação não é muito diferente, pois é recorrente em Eurípides a acusação de que Helena foi a causadora da guerra de Troia e, por conseguinte, dos males sofridos pelos gregos. ${ }^{5}$ Citamos, como exemplo, Hécuba (vv. 441-43): "Foi com os seus belos olhos que ela trouxe a pior das ruínas à prosperidade de Troia" (vv. 441-43). ${ }^{6}$ Porém, não é a possível responsabilidade que a personagem mítica possui sobre o início dos combates entre gregos e troianos que nos interessa nesse texto. Aqui nos chama a atenção a força e o poder de ação que uma personagem feminina adquire no imaginário helênico, caracterizado pela ideologia de submissão e da reclusão no interior do oĩ̌os, do grupo familiar (LESSA, 2010, pp. 67-73).

$\mathrm{Na}$ Ilíada a capacidade de ação de Helena é, em especial, notória. De acordo com Frederico Lourenço (2007, p. 48), ela "é uma peça basilar da engrenagem montada pelo poeta de condensar poeticamente a guerra de dez anos nos cinquenta e cinco dias da ação narrada.... Neste texto, propomos analisar a capacidade dada por Homero - tanto na Ilíada quanto na Odisseia—à ação de Helena a partir da dinâmica das relações de gênero. Lin Foxhall $(2013$, p. 1) destaca que a questão do gênero é essencial para a nossa compreensão da Antiguidade, como o é para o mundo que nos rodeia hoje.

\section{REFLETINDO SOBRE GÊNERO}

Mais do que sua beleza ou seu envolvimento com a guerra em Troia, a Helena épica nos possibilita analisar o espaço de ação feminino no período arcaico (séc. VIII ao VI a.C.) através da categoria teórica gênero. Antes de prosseguirmos é fundamental destacar que localizamos Homero no século VIII a.C ${ }^{7}$.Por mais que Helena desenvolva nas epopeias atividades culturalmente

4 Ver também: CALAME, 2017, p. 39-41.

5Heródoto (Histórias, II, 120) se mostra cético quanto ao fato dos troianos terem enfrentado uma guerra com os helenos por causa de uma mulher estrangeira. Ele sugere que Helena não estava em Troia, mas sim no Egito. Tucídides (I, 9) igualmente rechaçava a versão de que a perda de Helena tivesse sido a causa principal da guerra.

6 Em Hécuba, Helena aparecerá outras vezes como responsável pela guerra de Troia (vv. 265-70, 943-51). Trad. Maria do Céu Fialho e José Luís Coelho (2010).

7 No que se refere à questão da datação de Homero, seguimos: POMEROY, 1999, p. 32; ROMILLY, 2001, p. 11; VIDAL-NAQUET, 2002, p. 15. 
associadas pelos gregos às suas esposas legítimas, como a tecelagem (Ilíada, III, vv. 125-126), o gerenciamento das criadas (Ilíada, VI, vv. 322-323), a vinculação à roca (Odisseia, IV, v. 132), e receba por isso qualificações próprias do feminino, como "divina entre as mulheres" (Ilíada, III, v. 171; Odisseia, $\mathrm{XV}, \mathrm{vv} \cdot 123-125)$, ela age, inclusive, assumindo a condição de aedo, o que pode ser percebido no canto IV da Odisseia e no III da Ilíada, quando tece uma tapeçaria representativa dos conflitos entre helenos e troianos. Quando se espera das mulheres gregas o silêncio, Helena fala.

Como bem lembra Seijo (2017, p. 30), o status excepcional que Helena ocupa nos poemas homéricos faz com que ela seja a primeira e a última mulher mortal a falar na Ilíada (cantos III e XXIV), coisa que faz não apenas no interior da oỉí́ $\alpha$, da casa, mas também em público. Por causa disso, no âmbito da ficção, Helena é a primeira mulher que possui voz própria na história da literatura ocidental. Este fato per si já demonstra o caráter elevado de Helena, já que as outras mulheres mencionadas no poema no primeiro canto respectivamente Criseida e Briseida - não falam.

E o que a fala de Helena nos revela? De imediato, ela demonstra o que Joan Scott (1989) salientou, isto é, não foi tanto pela ausência de testemunhos e documentos que tivemos o silêncio e a invisibilidade femininos, mas sim pela noção de que tais informações não eram do interesse dos historiadores até décadas passadas. A fala de Helena ainda evidencia a possibilidade que as mulheres tinham de romper as fronteiras culturais que impunham a elas a reclusão e a passividade. Em linhas gerais, o que vemos são as mulheres conquistando espaços caracterizados pelas relações significantes de poder (cf. MATOS, 2017, p. 46). Neste momento é salutar destacar a constatação de Sarah Pomeroy (1999, p. 32) de que a personagem Helena é um caso à parte em todo aépica homérica, mas os mitos da Idade do Bronze estão repletos de poderosas personagens femininas, tais como: Clitemnestra, Hécuba, Andrômaca e Penélope.

Defendemos que tais percepções acerca do feminino se tornaram mais viáveis a partir dos debates oferecidos pela História das Mulheres e, mais recentemente, pela História de Gênero, com a qual iremos trabalhar.

Podemos considerar que a categoria gênero procura evidenciar que a construção do feminino e do masculino é relacional e não antagônica (BOEHRINGER; CUCHET, 2017, p. 17-8; BERNARD, 2003, p. 4). ${ }^{8}$ O

8 De acordo com Maria Izilda Matos (2017, p. 47 e 55-6), "a categoria gênero encontrou um terreno favorável na produção historiográfica contemporânea, desnaturalizando as identidades e postulando a dimensão relacional". 
que se busca com as pesquisas acerca de gênero é romper com as oposições binárias fixas e naturalizadas, tão remarcadas pelos autores gregos. ${ }^{9} \mathrm{~A}$ título de exemplo, citamos o Econômico de Xenofonte (VII, 22):

Já que ambas as tarefas, as do interior e as do exterior da casa, exigem trabalhos e zelo, desde o início, na minha opinião, o deus preparoulhes a natureza, a da mulher para os trabalhos e cuidados do interior, a do homem para os trabalhos e os cuidados do exterior da casa. ${ }^{10}$

Ao analisarmos a citação acima, que impõe às mulheres o espaço interno e ao homem o externo, verificamos que esta oposição binária e homóloga possui um caráter essencialista e a-histórico, ou de acordo com a concepção de Pierre Bourdieu (2002, p. 17 e 33), ela é "naturalizada" e se encontra inserida na esfera da dominação masculina. Mas aqui vale um destaque para Helena. No canto III da Ilíada (vv. 390-391) ela rompe esse esquematismo. Ela se encontra fora de casa, nas muralhas de Troia, quando Afrodite vai até ela e ordena que vá para o tálamo satisfazer o seu esposo. Temos com o caso de Helena um exemplo claro da possibilidade de distanciamento da ideologia da reclusão por parte dos grupos femininos. No geral, Helena está presente frequentemente nos êxitos que têm lugar no interior de Troia (BETTINI; BRILLANTE, 2008, p. 28).

Diferente do essencialismo biológico, o gênero evidencia que as referências culturais são sexualmente produzidas por símbolos e discursos, pela linguagem e relações de poder (MATOS, 2017, p. 47). Refletindo acerca da relação entre gênero e espaço físico, LinFoxhall e Gabriele Neher (2013, p. 1) entendem que o conceito de gênero é um elemento chave da organização social e política. Logo, sinalizam para a sua conotação de poder. Já Judith Butler (2017, p. 26) é clara ao enfatizar que “...o gênero é culturalmente construído; consequentemente, não é nem o resultado casual do sexo nem tampouco tão aparentemente fixo quanto o sexo." ${ }^{11}$

É recorrente entre os pesquisadores da História de Gênero a afirmação de que o conceito gênero resulta de uma construção sociocultural. J. Scott (1995, p. 86; 1994, p. 20) já havia apontado para essa questão ao constatar que "o gênero é um elemento constitutivo das relações sociais baseadas nas

9 Sobre essa questão um trabalho interessante é o de James Davidson (2013, p. 107-24).

10 Tradução de Anna Lia A. de Almeida prado (1999).

11 Lin Foxhall (2013, p. 2) atenta para o fato de que a presença do elemento biológico no gênero - masculino e feminino-e em seus corpos físicossignifica que há algo relativamentefixo e compartilhado sobre o gênero ao longo da história humana. 
diferenças percebidas entre os sexos". P. Bourdieu (2002, p. 33-4) destaca a construção social da categoria gênero, assim como o seu aspecto relacional. Em sentido próximo, Sandra Boehringer e Violaine S. Cuchet (2017, p. 17) apontam para o fato de que os trabalhos mais recentes de História de Gênero se interessam pelo estudo dos discursos e das ideologias sobre a masculinidade em diferentes épocas e nos diferentes espaços de atividades sociais. $\mathrm{O}$ mesmo acontece no trabalho de Maria Izilda de Matos (2017, p. 55) quando ressalta que "...as percepções sobre masculino e feminino como dependentes e constitutivas das relaçóes culturais; procurando não essencializar sentimentos, posturas e modos de ser e viver de ambos os sexos". Assim, podemos concluir que gênero adquire a conotação de uma organização social da diferença sexual, baseada nos saberes, nas instituições, no poder e práticas produzidas pelas culturas sobre as relações entre homens e mulheres/masculino e feminino. Em síntese, o gênero é um "sexo social", determinado pela comunidade, e evoluindo no tempo e no espaço (BERNARD, 2003, p. 4).

Por tudo o que explanamos até o momento, podemos afirmar que a relação entre Helena, Menelau e Páris/Alexandre pode ser reveladora de um dos aspectos da dinâmica entre os gêneros na sociedade grega arcaica. Para além da discussão acerca do rapto de Helena (HERÓDOTO, Histórias, I,4) ou de sua sedução-o que alteraria fortemente a relação entre o feminino e o masculino: no primeiro caso teríamos uma ação de violência submetida a Helena e cometida por Páris; já no segundo, a espartana abandona a condição de vítima e assume o protagonismo na sua relação com o príncipe troiano —, temos uma situação singular na relação Helena-Menelau, implicando em perda de poder e de prestígio para o rei espartano. Há um claro desrespeito de Páris, hóspede de Menelau, quando retira a sua esposa de casa e a leva para Troia. Porém, o que nos interessa mais diretamente nesse momento é a condição de Menelau. Ele se torna rei de Esparta pelo casamento com Helena, filha de Tíndaro, soberano espartano (POMEROY, 1999, p. 35-6; BETTINI; BRILLANTE, 2008, p. 27). Logo, perder Helena significava perder o seu poder político.

Uma releitura dos textos antigos, no nosso caso dos poemas de Homero, a partir das relações de gênero permitirá ler a história de Helena inserida nos valores gregos de uma forma mais ampla e restituí-la a sua condição de agente.

\section{A ação épica de Helena}

Para analisarmos a Helena homérica, dois cantos serão o nosso ponto de partida: o canto III da Ilíada, no qual Páris/Alexandre e Menelau se enfrentam 
em um $\alpha \dot{v} \tau i ́ \beta 10 v \mu \alpha \chi \varepsilon ́ \sigma \alpha \sigma \theta \alpha 1$, um combate singular, e disputam "por Helena e por tudo o que lhe pertence" (HOMERO, Ilíada, III, v. 70) ${ }^{12}$; e o canto IV da Odisseia, em que Helena, de novo em Esparta, recebe os príncipes Telêmaco e Pisístrato, que procuram notícias do paradeiro de Odisseu. Naturalmente outras passagens de ambos os poemas servirão aos nossos propósitos, mas o que nos interessa particularmente nestes dois cantos é o relevo dado por Homero à personagem em questão.

O canto III da Ilíada é por excelência o canto de Helena, pois estarão presentes nas ações da personagem, como veremos a seguir, todos os contornos que lhe são mais característicos: a ambiguidade, a insubmissão, a astúcia e o carisma. Não por acaso, Rachel Bespallof (1965, p. 103) dirá que “ao lado dos guerreiros e acima deles, Helena é a tranquilidade e a amargura que surgem no meio da batalha, lançando sua sombra fria sobre vitórias e derrotas, sobre os vivos e sobre os milhares de mortos". De certo modo, é esta a epítome do canto III, seja na teicoscopia, seja na tapeçaria.

Elegemos quatro eixos de análise que são pertinentes a nossa proposta de ler Helena sob a ótica do gênero. Cada um deles pretende demonstrar como as ações da personagem, nos poemas de Homero, de alguma maneira subvertem as relações de gênero vigentes e alçam a personagem a um lugar de destaque entre as mulheres descritas pelo poeta. Falaremos primeiro sobre a subversão técnico-poética, em que a tecelagem de Helena ganhará destaque; em seguida, sobre a subversão espacial, já que ela tem acesso a espaços que não são aqueles tradicionalmente estabelecidos para as mulheres; analisaremos a subversão ética, em que veremos como as ações da personagem para com seus interlocutores demonstram certo tipo de $\tilde{\eta} \theta 0 \varsigma$, de caráter; por último, colocaremos em pauta a subversão discursiva, na qual demonstraremos a função aédica de Helena no que diz respeito ao $\mu$ ṽ $\theta$ os, um tipo particular de discurso geralmente atribuído aos homens.

\section{Subversão técnico-poética}

Helena está tecendo um $\mu \varepsilon^{\prime} \gamma \alpha \nu$ i $\sigma \tau$ òv, uma grande tapeçaria, quando a deusa Íris vem a seu encontro tomando a forma de Laódice, sua cunhada.

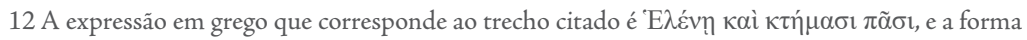
dativa de $\kappa \tau \tilde{\eta} \mu \alpha$, utilizada como parte de uma fórmula métrica por Homero, pode indicar que os Aqueus combatem não só por Helena, mas também por suas posses, o que sugere que ela poderia ter levado consigo, na ocasião de seu rapto por Páris, bens do palácio espartano que pertenciam a Menelau. Conferir o argumento que Proclus faz da Cypria em West (2003, p. 69). A fórmula

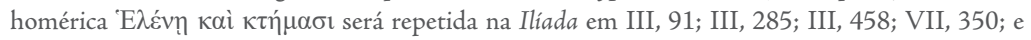
XXII, 114. Maria Martha Pimentel de Mello (1996, p. 216) chega a afirmar que "o motivo real da guerra [de Troia] está ligado à posse de riqueza” em detrimento ao rapto de Helena. 
A deusa quer avisá-la que Páris e Menelau estão prestes a combater. Chama atenção o fato de que Íris, uma deusa de particular importância na Ilíada, portando-se como a mensageira dos deuses, age aparentemente por conta própria, sem que nenhum dos outros deuses tenha requisitado a sua interferência ${ }^{13}$. De todo jeito, Homero faz questão de destacar as qualidades da tapeçaria de Helena nos versos seguintes (HOMERO, Ilíada, III, vv. 125128):

Encontrou-a no palácio, tecendo uma grande tapeçaria de dobra dupla, purpúrea, na qual ela bordava muitas contendas de Troianos domadores de cavalos e de Aqueus vestidos de bronze contendas que por causa dela tinham sofrido às mãos de Ares.

Na cultura grega antiga, a atividade da tecelagem é tipicamente atribuída às mulheres. Neste primeiro momento, Helena está desempenhando a função de uma esposa ideal, reclusa no interior do palácio enquanto tece. Cena muito semelhante vai acontecer no canto IV (vv. 120-35) da Odisseia, pois Helena se apresentará para Telêmaco e Pisístrato tendo acabado de sair de seu tálamo, acompanhada por servas que trazem consigo os materiais de tecelagem que a rainha havia ganhado no Egito.

Em Homero, a tecelagem pode ser compreendida, a nosso ver, por três vias: em primeiro lugar, como tarefa econômica vinculada à manutenção do lar e do esposo, e que independe dos estratos sociais: "Nobres ou escravas, todas as mulheres participam, ao menos, do tecido. Tecem Helena e Penélope, tecem as escravas ofertadas por Agamêmnon, tecem as servas" (FASANO, 2018, p. 13);em segundo lugar, como um recurso metalinguístico que associa a feitura da trama do tecido com a trama do poema - basta ver que o tema da tapeçaria de Helena, as muitas contendas "de Troianos domadores de cavalos e de Aqueus vestidos de bronze" (HOMERO, Ilíada, III, v. 127), vai se repetir logo adiante (v.131) na fala de Íris/Laódice, que a convida para observar "as façanhas espantosas / de Troianos domadores de cavalos e de Aqueus vestidos de bronze". Trata-se, portanto, de metapoesia ${ }^{14}$. Por último, a tecelagem no

13 A hipótese de Kirk (1985, p. 279) é a de que a intenção do poeta é mostrar o envolvimento divino mesmo nesse tipo de procedimento humano. $\mathrm{O}$ autor defende que, depois do julgamento de Páris, Helena tornou-se quase um "peão" divino (divinepawn) nas mãos dos deuses, como se todas as ações em torno de Helena tivessem um quê de divino. Ele destaca também que a convocação de Íris prepara o caminho para o diálogo com Afrodite mais tarde.

14 Sobre o elemento metapoético ligado a Helena, conferir o texto de André Malta (2016); para a associação entre o trabalho feminino e o canto, ver o livro de Andromache Karonika (2014, p. 24 e seguintes); para as implicaçóes metalinguísticas, ver o texto de Kenaan (2001, p. 182-196.). 
imaginário grego é também um canal de comunicação subversivo. As mulheres podem, por meio desta atividade, romper com o silêncio a qual são confinadas e atingir outros públicos ${ }^{15}$. Lilian Sais ${ }^{16}$ (2016, p. 124) observa a relação entre a fala e a tessitura:

Na sociedade grega antiga, falar não é uma atividade que, a priori, cabe às mulheres. Em vez de falar, elas tecem. Enquanto isso, os homens falam, cuidam das questóes de política, guerra e sociedade, entre outras coisas. As mulheres, silenciadas, tecem, produzindo uma "fala metafórica", ou seja, fazendo um "material silencioso falar".

Desta maneira, Helena poderia estar "falando"17 através do que tece, o que leva West (2011, p. 130) a dizer que o "desenho [na tapeçaria] reflete uma preocupação cheia de remorso com a responsabilidade que [Helena] tem diante das consequências de suas ações"18. $\mathrm{O}$ rasgo de ambiguidade em torno da tecelagem ao mesmo tempo a aproxima de uma atividade masculina - a fala, especialmente a fala pública -, mas sem deixar de ser uma tarefa das mulheres. Não podemos perder de vista que o estratagema por meio do qual Penélope, na Odisseia, engana os pretendentes por três anos é também oriundo do tear: durante o dia a filha de Icário tecia, e à noite desfazia a trama da mortalha.

Outra evidência do caráter ambíguo e subversivo em torno da tecelagem é de ordem linguística. Em Homero, o campo semântico do verbo tecer

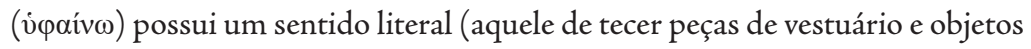

15 Há, em Homero, inclusive, uma conexão entre a tecelagem e o canto, o que aproxima ainda mais a atividade poética (masculina) da atividade fabril (feminina): no canto $\mathrm{V}$ da Odisseia Hermes é enviado por Zeus à ilha de Calipso para comunicar à deusa a deliberação de Zeus de que Odisseu deve retornar à Ítaca. Hermes a encontra em sua gruta, onde “(...) ela cantava com linda voz; / e com lançadeira dourada trabalhava ao seu tear" (HOMERO, Odisseia, V, vv. 51-62).

16 Em sua tese de doutorado, a autora cita expressões do artigo "Language and the Female in Early Greek Thought", de Ann Bergren, originalmente publicado em 1981 no jornal Aretbusa. Em 2008 o texto de Bergren foi republicado pelo Center of Hellenic Studies, da Universidade de Harvard. As expressões em aspas são, portanto, do texto original de Bergren. Ver Bergren (2008).

17 Existe um mito exemplar a respeito da relação entre tessitura e fala: Tereu casou-se com Procne, mas estuprou em segredo Filomela, irmã de Procne, e cortou sua língua; Filomela tece então uma túnica contando o que Tereu havia feito e presenteia sua irmã, que mata o filho que havia tido com seu marido e o serve em um jantar ao próprio. Algumas das fontes que contam o mito são: Ovídio, Metamorfoses, VI, 412-674; Apolodoro, Biblioteca, 3.14.8; Pausânias, Descrição da Grécia, 1.5.4. Uma peça de Sófocles chamada Tereus, da qual restam alguns fragmentos, também utilizou esta mesma matéria mítica. Conferir: PEARSON, 1917.

18 André Malta (2016, p. 21) também cita este trecho de West, destacando a abordagem sua "psicológica". 
domésticos) e um sentido figurado ou metafórico (o de tecer mitos, planos, enganos e astúcias). As duas formas são produtivas tanto na Ilíada quanto na Odisseia ${ }^{19}$ e revelam que, pelo menos para a tradição épica, a ação de tecer e de tramar estavam conectadas semanticamente, e, nesse sentido, Penélope talvez seja a personagem que melhor encarna as duas acepçóes do verbo grego. $\mathrm{O}$ caso de Helena, entretanto, difere do caso de Penélope; pois se a tecelagem de Penélope é do tipo objetivo (se destina a um fim, o dolo) e funcional (a mortalha possui um valor narrativo na Odisseia), a tecelagem de Helena é do tipo subjetivo e decorativo (ela tece uma peça na qual enxerga a si própria e seu papel na guerra, e que não tem valor concreto ou narrativo), pois nunca pretendeu ser outra coisa além do que éł a sua versão, em imagem, da guerra de Troia.

\section{Subversão espacial}

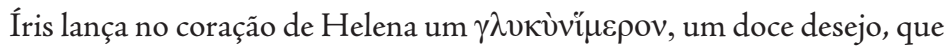
faz com que ela se recorde de seu primeiro marido, Menelau, da sua cidade e dos seus progenitores. Em outras palavras, Helena se lembra da sua vida espartana, e por causa disso se precipita para fora do tálamo "com lágrimas nos olhos" (HOMERO, Ilíada, III, v. 142). Ela se dirige às Portas Esqueias- não sozinha, mas acompanhada por duas criadas, Etra e Clímene - para assistir ao já referido combate singular entre Páris e Menelau, duelo este que decidirá o seu futuro. Nas muralhas estarão Príamo e outros sete anciões regentes de Troia, que pela idade não têm mais condição de guerrear. Assim que percebem a aproximação de Helena, sussurram "palavras aladas" (HOMERO, Ilíada, III, vv. 156-160):

Não é ignominia que Troianos e Aqueus de belas cnêmides sofram durante tanto tempo dores por causa de uma mulher destas! Maravilhosamente se assemelha ela às deusas imortais.

Mas apesar de ela ser quem é, que regresse nas naus; que aqui não fique como flagelo para nós e nossos filhos.

Algumas questóes linguísticas merecem ser destacadas. A palavra grega que corresponde à "ignomínia” é vé $\mu \varepsilon \sigma ı \zeta$, palavra cara à tradição épica, pois 
segundo algumas versões a deusa Nêmesis teria sido a mãe de Helena ${ }^{20}$. Haveria aqui uma referência homérica a esta tradição? De qualquer maneira, o sentido do verso, como defende Kirk (1985, p. 285), é o de que os nem troianos nem os aqueus devem sentir justa indignação, oủvé $\mu \varepsilon \sigma ı \zeta$, diante de um ato injusto. Ou seja, nem gregos nem troianos devem se sentir desonrados por lutarem por ela. Helena é vista pelos anciões de maneira ambígua, e o uso do advérbio $\alpha i v \tilde{\omega} \zeta$, que pode ser traduzido tanto por "extremamente" quanto por "terrivelmente", reforça ainda mais tal condição da personagem - que muito

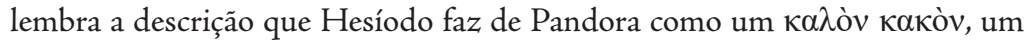
belo mal (HESIODO, Teogonia, v. 585). De qualquer maneira, Helena está fora do palácio, sobre as muralhas, e terá início a teicoscopia, a identificação e a descrição dos maiores heróis do exército grego. Para Minchin (2007, p. 185), Príamo se dirige a Helena não porque desconheça os principais heróis aqueus mesmo depois de nove anos de guerra, mas porque quer criar laços com ela. Seja qual for o objetivo do rei, Helena, em público, tece comentários sobre personagens como Agamêmnon, Odisseu e Ájax, e ele aprova suas palavras (HOMERO, Ilíada, III, v. 204). Precisamos levar em conta nesta passagem a já referida caracterização que Xenofonte faz dos espaços destinados à ação da mulher, que pertencem ao interior da casa. Aqui, vemos Helena ocupar um espaço que não condiz com a dicotomia espacial típica da época clássica. Em relação a isso, Katz (1981, p. 21) vai dizer que no período clássico os gregos habitavam um mundo dividido em que masculino e feminino eram princípios de organização espacial, porém, segundo a helenista, "nos poemas homéricos, por contraste, a dicotomia de papéis, atributos e esferas de atividade é muito menos rígida, e a oposição entre domínios "públicos" e "privados" é discutivelmente não existente.

20 De acordo com os fragmentos da Cypria (um poema épico de doze cantos que contaria a origem da guerra de Troia e os eventos que antecederam o cerco à cidade), Helena não é filha de Zeus e Leda, mas de Zeus e Nêmesis, que teria sido estuprada pelo Cronida (Conferir o fragmento da Cypria, segundo Athenaeus, em West, 2003, p. 89). Nêmesis é uma divindade ligada à justa distribuição, à justa indignação e à retribuição por males recebidos; é uma deusa tutelar do equilíbrio. Em Homero, Helena é sempre referida como "filha de Zeus", mas o poeta nunca nos diz objetivamente quem é sua mãe. Conferir II., III, 199; III, 418; III, 426; e Od., IV, 184; IV, 219; e XXIII, 218. Quando Odisseu acessa o Hades para consultar Tirésias sobre seu retorno, ele vê a alma de Leda, que Homero descreve da seguinte maneira (HOMERO, Odisseia, XI, 298-300): "Vi depois Leda, a esposa de Tíndaro, / que a Tíndaro deu dois filhos de ânimo rijo / Castor, o domador de cavalos, e Pólux, o pugilista”. Neste trecho, não há menção a Helena como filha de Leda. No canto III da Iliada, entretanto, Helena pergunta sobre seus irmãos, Cástor e Pólux, (HOMERO, Ilíada, III, 234-242), e diz que compartilham da mesma mãe. Segundo a Biblioteca de Apolodoro (3.10.7), entretanto, um pastor teria encontrado o ovo resultante da união entre Zeus e Nêmesis e entregado a Leda, que teria criado Helena como sua própria filha. Fica a questão: saberia Helena quem é sua verdadeira mãe? 
Se tomarmos os poemas de Homero como referências possiveis do que o século VIII a.C experimentou em termos de relações de gênero, podemos então afirmar que ali estão os esboços imprecisos e indefinidos do que a Atenas de Xenofonte experimentaria séculos mais tarde. Por mais que em Homero não haja uma divisão evidente entre os espaços que homens e mulheres podem ocupar, como aponta Katz, encontramos algumas passagens do poema que demonstram tentativas de reclusão do feminino. Vejamos por exemplo a recomendação que Telêmaco faz a Penélope, tendo ela censurado o aedo Fêmio por cantar o regresso dos aqueus (HOMERO, Odisseia, I, vv. 356-359):

\author{
Agora volta para os teus aposentos e presta atenção \\ aos teus lavores, ao tear e à roca: e ordena às tuas servas \\ que façam os seus trabalhos. Pois falar é aos homens \\ que compete, a mim sobretudo: sou eu quem manda nesta casa.
}

Telêmaco ordena à mãe que se retire do $\mu$ ź $\gamma \alpha \rho o v$, da sala principal do palácio, pois é lá que os pretendentes estão enquanto ouvem a performance de

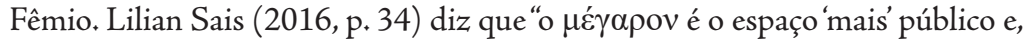
portanto, masculino da casa; é lá que são recebidos os hóspedes. No caso do palácio de Odisseu, é lá que estão instalados, todos os dias, os pretendentes e a desordem que eles trazem", e conclui dizendo que esse $\mu \dot{\varepsilon} \gamma \alpha \rho \circ$ em especial "é mais público (e, então, masculino) do que poderíamos supor em um primeiro momento". Percebemos, então, que por mais que não haja nos poemas de Homero uma segregação espacial rígida do feminino, existem espaços mais ou menos "apropriados" para uma mulher ${ }^{21}$.

A passagem de Telêmaco e Penélope nos interessa porque mostra que a presença feminina no espaço público não é um evento ordinário. $\mathrm{A}$ presença de Helena nas muralhas de Troia, mesmo acompanhada por suas criadas, demonstra como seu status é privilegiado, e mais: além de ocupar um assento ao lado de Príamo ("Chega aqui, querida filha, e senta-te ao meu lado"; HOMERO, Ilíada, III, v. 162), Helena fala e é ouvida. Coisa semelhante ocorre na Odisseia durante a despedida de Telêmaco e Pisístrato, em que ela está do lado de fora do palácio observando a partida dos príncipes e um prodígio acontece: uma águia voa ao lado do carro dos dois segurando nas

\footnotetext{
21 Nancy Felson e Laura Slatkin (2006, p. 114) assinalam que "é tradicionalmente atribuído às mulheres o ritual de cuidar dos mortos, e em particular a performance do lamento funeral, um dos poucos modos de discurso das mulheres permitido na antiguidade". É por isso que a cena do discurso de Helena no canto XXIV da Ilíada não nos interessa em termos de subversão espacial. É importante assinalar, entretanto, que Helena é a última mulher do poema a falar, o que ressalta ainda mais a sua condição particular.
} 
garras um ganso branco. Telêmaco pergunta a Menelau para quem este sinal dos deuses havia sido enviado. Enquanto o rei de Esparta tenta decifrar o enigma, Helena toma a palavra e interpreta o prodígio - e Telêmaco diz em resposta (HOMERO, Odisseia, XV, vv. 180-181): "Que assim queira Zeus, o esposo tonitruante de Hera / Então eu te dirigiria preces, como se fosse uma deusa". Novamente, em público, sob os olhos de homens e mulheres, e respondendo no lugar do marido, Helena fala - e é ouvida.

\title{
Subversão ética
}

Se Aristóteles afirma em sua Poética (1450B, 5-10) que o ĩ $\theta$ o, o caráter, se manifesta nas escolhas deliberadas, ou naquilo que se prefere ou se evita, precisamos refletir sobre as escolhas, açóes e falas de Helena para verificarmos o tipo de caráter da personagem de Homero. No referido episódio da teicoscopia, Príamo pede a Helena que identifique o aqueu "belo", "alto e forte", de "aspecto nobre" e que "parece um rei" (HOMERO, Ilíada, III, vv. 163-170). E ela, por sua vez, responde o ancião com as seguintes palavras (HOMERO, Ilíada, III, vv. 172-180):

\author{
Venerando és tu para mim, querido sogro, e terrivel: \\ quem me dera ter tido o prazer da morte malévola, \\ antes de para cá vir com teu filho, deixando o tálamo, \\ os parentes, a minha filha amada e a agradável companbia \\ das que tinham a minha idade: mas isso não pôde acontecer. \\ E é por isso que o choro me faz definhar. \\ Mas responder-te-ei àquilo que me perguntas. \\ Este é o Atrida, Agamêmnon de vasto poder, \\ que é um rei excelente e um forte lanceiro. \\ Era cunbado da cadela que sou; se é que foi mesmo.
}

A fala de Helena, a sua primeira no poema, é marcada por um tom de lamento, arrependimento e tristeza em relação ao curso dos acontecimentos; ela diz, olhando em retrospectiva, que preferia ter morrido ao invés de ir para Troia com Páris/Alexandre, e lamenta ter deixado para trás uma teia de relaçóes sociais. Karanika (2014, p. 27) percebe no discurso de Helena uma tentativa de utilizar a sua responsabilidade nos eventos da guerra de maneira estratégica, como se ela estivesse "tecendo uma trama" em um processo maior de controlar a opinião dos outros sobre si mesma.

Portando-se dessa maneira, Helena assume uma posição feminina tradicional, mas com o propósito evidente de manipular o que dizem a seu respeito. Antes de responder a pergunta de Príamo, Helena faz questão de 
mostrar como se sente, mesmo que o sogro nada tenha perguntado. E encerra chamando a si mesma de $\kappa v v \omega ́ \pi เ \delta o \zeta$, cadela $^{22}$. Para entendermos a dimensão

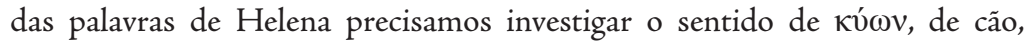
em Homero. Seijo (2017, p. 18) chama atenção para o fato de que ela está "manifestando o pesar e a vergonha que lhe causa ter sido a causa da guerra", pois:

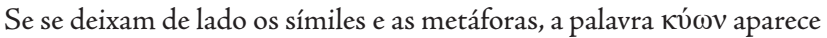
quarenta vezes na Ilíada, e trinta e cinco dessas aparições fazem referência a cães que devoram cadáveres humanos. Ser alimento dos cachorros constitui uma ameaça a um herói épico, dado que lhe privaria de uma morte gloriosa.

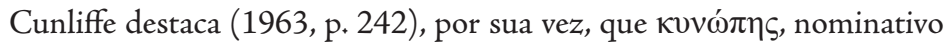

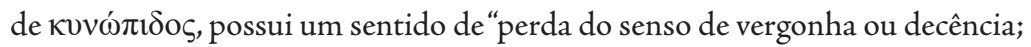
[qualifica um indivíduo como] desavergonhado, imprudente, escandaloso". Ambas as definições são coerentes no contexto, uma vez que Helena pode estar se qualificando como causa da guerra de Troia, pois faz com que heróis tombem no campo de batalha, e, paralelamente, condena a si mesma por ter se submetido, com Páris/Alexandre, às delícias de Afrodite. Mas por que Helena, além manifestar arrependimento, chama a si mesma de cadela? A hipótese de Roisman (2006, p. 13-14) é a de que, para conquistar a simpatia de seus interlocutores, de quem ela necessita, em especial Príamo, Helena encena deliberadamente um tipo feminino estereotipado, evidenciando "sua habilidade e competência na hora de fazer com que as pessoas se sintam bem e de cuidar de si mesma ao ser uma mulher que não é bem-vinda em um ambiente hostil".

Outro traço evidente da personalidade de Helena pode ser percebido na sua terceira resposta a Príamo, na qual ela identifica Ájax e Idomeneu. Já assinalamos que ela faz questão de comentar coisas que não foram perguntadas, mas que nem por isso recebe uma repreensão ou censura por parte dos anciões. Nessas falas aparentemente ingênuas de Helena podemos encontrar críticas sutis ou mesmo ironias finas que passam despercebidas se não tentarmos romper a superficialidade do texto e adentrar o contexto ficcional do poema. $\mathrm{Na}$ passagem abaixo Helena revela não ter notícias dos irmãos, mesmo que nenhum dos anciões tenha perguntado qualquer coisa sobre eles (HOMERO, Ilíada, III, vv. 236-242). 
Só não consigo ver dois condutores de hostes:

Castor domador de cavalos e o pugilista Polideuces,

meus irmãos, que minha mãe deu à luz.

Ou não seguiram para cá, da agradável Lacedemônia,

ou embora tenham vindo nas naus preparadas para o alto-mar, não querem agora participar neste combate de homens,

por recearem os vergonhosos insultos a meu respeito.

Helena não sabe, mas seus irmãos morreram, e Homero faz questão de dar essa informação nos versos seguintes (243-4). De acordo com a tradição épica, a morte de Cástor e Pólux seria o tema do terceiro canto da Cypria, se podemos levar em conta o argumento de Proclus. Se pensarmos nos efeitos da performance do aedo sobre a audiência, podemos conjecturar que a intenção de Homero ao revelar esse tipo de informação após a fala de Helena é criar um contraste entre a sua situação em Troia, que há noves anos vive em ignorância no que diz respeito ao mundo para além das margens do Escamandro, e a realidade ficcional criada pelo poeta. Seu estado é o de um isolamento pleno, como se ela ficasse confinada ao palácio enquanto a guerra se desenrola nas planícies à frente dos portões da cidade. Helena não vê Príamo e Páris/ Alexandre como parte de sua família (o que pode ser percebido no verso 174 do mesmo canto quando, ao se dirigir a Príamo, se refere à Páris/Alexandre "teu filho", e não "meu marido"), mas deixa claro que sente falta da vida que levava em Esparta e das relações que mantinha lá (vv. 175-176). Em Troia Helena não é mais do que o monumento vivo da desgraça dos troianos, visão esta sintetizada no verso 160 nos sussurros dos ancióes ("que aqui não fique como flagelo para nós e nossos filhos"). Como observa Nicole Loraux (1995, p. 195-196), Helena transita entre ser objeto de prazer e sofrimento - o que é brilhantemente colocado no verso 158 deste mesmo canto com o uso do advérbio $\alpha i v \tilde{\omega} \varsigma$, como já foi apontado.

Apesar disso, Helena faz questão de não ser uma simples marionete de deuses e homens. Ela não se submete facilmente aos caprichos das divindades, em especial Afrodite, pois tem uma reputação a zelar, mesmo que a maioria tenha uma visão negativa a seu respeito. Quando Afrodite retira Páris do combate singular com Menelau e o leva para o tálamo, a deusa se transforma em uma velha cardadora de lã, que afirma estar Páris/Alexandre à sua espera no leito nupcial. Helena, por meio da astúcia, percebe de imediato que a pessoa a sua frente é uma deusa e dá a ela uma resposta com palavras ásperas (HOMERO, Ilíada, III, vv. 399-412).

Deusa surpreendente! Por que deste modo queres me enganar?

$\mathrm{Na}$ verdade me levarás para mais longe, para uma das cidades 
bem habitadas da Frígia ou da agradável Meônia, se também lá existir algum homem mortal que te é caro, visto que Menelau venceu o divino Alexandre e agora intenta levar para casa a mulher detestável que eu sou.

Por isso agora aqui vieste como urdidora de enganos.

Vai tu sentar-te ao lado dele, abjura os caminhos dos deuses

e que não te levem mais teus pés ao Olimpo!

Em vez disso estima-o sempre e olha por ele, até que ele te faça sua mulher, ou até sua escrava!

Mas para lá eu não irei - seria coisa desavergonhada tratar do leito àquele homem. No futuro as Troianas

todas me censurariam. Tenho no peito dores desmedidas.

A réplica de Helena a Afrodite pode ser dividida em três momentos, e desses três momentos três fatos são reveladores. Em primeiro lugar, ela pensa que a deusa pretende enganá-la, levando-a para um outro favorito seu que não é Páris/Alexandre ou Menelau (vv. 400-404); isto demonstra que a personagem está ciente de que o seu destino depende dos caprichos da deusa. Em segundo lugar, Helena dirige palavras duras a Afrodite, sugerindo que ela se torne mulher ou escrava de Páris/Alexandre (vv. 408-409); mais do que desobedecer deliberadamente uma ordem da deusa, ela demonstra indiferença tanto em relação a Afrodite como também no que diz respeito ao tipo de relação que ela pode vir a ter com seu marido. Por último, Helena ainda se preocupa com a sua reputação entre as mulheres troianas, pois teme que, caso ceda, ela acabe se tornando um motivo de escárnio por se deitar com um homem infame. No fim das contas, seu protesto de nada adiantará, pois ela se verá obrigada a dividir o leito com Páris/Alexandre mesmo contra a sua vontade. No entanto, sua falaseguinte, dirigida ao marido, mostra não só a sua preferência por Menelau

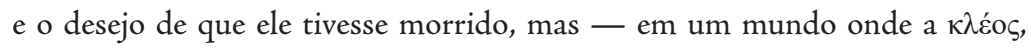
a glória, é conquistada diante dos olhos dos outros na guerra - escancara a covardia de Páris/Alexandre, que neste momento, inflamado por Afrodite, a deseja como nunca, patético como sempre (HOMERO, Ilíada, III, vv. 428436):

Voltaste da guerra. Quem me dera que lá tivesses morrido, vencido por homem mais forte, como é o meu primeiro marido!

$\mathrm{Na}$ verdade te vangloriaste no passado de seres melhor queMenelau, dileto de Ares, pela força das mãos e da lança! Vai lá agora desafiar Menelau, dileto de Ares, para de novo combater contigo, corpo a corpo. Mas eu própria te mando desistir: contra o loiro Menelau não combatas um combate corpo a corpo nem queiras contra ele lutar insensatamente, para que não sejas vencido pela lança dele. 
No canto VI, Helena voltará a dirigir palavras amargas para Páris/ Alexandre em um diálogo com Heitor. Ela, que estava desempenhando atividades femininas, toma a palavra mesmo que nenhum dos príncipes troianos tenham perguntado a ela qualquer coisa, e diz a Heitor, na frente do marido, que preferia ter sido esposa de um homem mais digno, e que Páris/ Alexandre "não está no seu perfeito juízo, nem alguma vez estará" (HOMERO, Ilíada, VI, vv. 350-353). Helena não faz questão alguma de esconder o seu desprezo por seu atual marido, um ato de insubmissão impensável que vai nacontramão do comportamento esperado de qualquer esposa grega.

\section{Subversão discursiva}

Resta destacar, por último, de que maneira os discursos de Helena a Pisístrato e Telêmaco (tanto o do canto IV da Odisseia quanto o do canto $\mathrm{XV}$ ) possuem características de uma fala incomum ao gênero feminino. Para isso, precisamos resgatar a já referida censura de Telêmaco a Penélope no canto I, na qual o filho de Odisseu diz que "falar é aos homens que compete" (HOMERO, Odisseia, I, vv. 358-359). O sentido da frase é o de que a fala é um assunto dos homens, e esta fala corresponde à palavra grega $\mu$ ṽ os. Mas qual o sentido deste $\mu \tilde{v} \theta$ os? Lilian Sais (2016, p. 34) diz que "Telêmaco usa o termo referindo-se não a qualquer fala, mas sim à fala pública”. Portanto, falar na presença de hóspedes (como é o caso dos pretendentes, ainda que hóspedes indesejados e impertinentes) e em espaços públicos (como por exemplo, o lado de fora do palácio de Menelau, ou mesmo nas muralhas de Tróia) são atividades que não fazem parte da esfera feminina, pois às mulheres o $\mu \tilde{0} \theta 0 \varsigma$ não compete. Apesar disso, vimos em várias ocasiões Helena quebrar estes padróes de comportamento e tomar a palavra, falando sobre o que deseja; por causa disso, analisaremos agora algumas propriedades das falas da personagem.

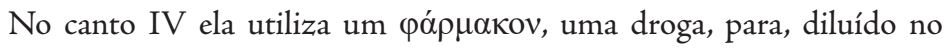
vinho, anular a dor que Telêmaco, Pisístrato e Menelau sentiam ao rememorar o passado. Ela aprendera tais habilidades com Polidamna, a rainha egípcia esposa de Ton, durante o período em que ela e Menelau estiveram por lá. Helena serve o vinho adulterado e toma a palavra (HOMERO, Odisseia, IV, vv. 235-239).

Atrida Menelau, criado por Zeus, e vós que aqui estais, filhos de homens nobres! Ora a um, ora a outro, dá Zeus o bem e o mal; pois tudo ele pode.

Sentai-vos agora na sala, comprazei-vos com ofestim e deleitai-vos com discursos: por mim, algo direi de adequado. 
Aqui vemos a personagem não só controlando as emoções de seus interlocutores através de uma droga especial, mas ocupando o lugar de contadora de histórias para o deleite de seu marido e de seus hóspedes. Doyle (2010, p. 6) enfatiza seu poder magnético ao dizer que "Helena reconhece Telêmaco imediatamente e no seu discurso de abertura ela chama atenção da sua audiência intencionalmente para suas habilidades perceptivas e de controle narrativo". Não por acaso, então, os "discursos" aqui são, em grego, $\mu$ $\theta 0 ı \varsigma$, indo totalmente contra a determinação anterior de Telêmaco de que não compete às mulheres falar. Helena não só fala, mas conta um $\mu \tilde{v} \theta 0 \varsigma$, uma história sobre um encontro secreto entre ela e Odisseu durante a guerra de Troia. O filho de Laertes entrou em Troia disfarçado de mendigo, e Helena - como era de se esperar, já que fez a mesma coisa com Telêmaco e Afrodite — o reconhece. Não só o reconhece, mas o banha, unta seu corpo com azeite e o veste; e por mais que a história pareça absurda (afinal de contas, como uma princesa troiana conseguiria agir dessa maneira em segredo?), a oportunidade de contá-la com tantos detalhes, principalmente banhando um homem que não fazia parte de sua família, mostra como Helena subverte o que se espera de uma esposa, de uma princesa ou de uma rainha.

No canto XV (verso 171), na interpretação do prodígio dos pássaros a Telêmaco e Pisístrato, Homero novamente utilizará a palavra $\mu$ ṽ $\theta$ o $̧$ para descrever e qualificar o tipo de fala de Helena. Aqui o poeta utiliza uma fórmula recorrente aos discursos masculinos, o pá $\tau$ $\mu \tilde{0} \theta 0 v$. Lilian Saias (2016, p. 36) explica que essa fórmula, na Odisseia, introduz falas que possuem certa autoridade, como é o caso aqui: Helena toma a palavra de Menelau e interpreta um prodígio que assegura o retorno de Odisseu para Ítaca. No fim das contas, Telêmaco só obtém o que veio procurar — notícias sobre o pai por meio da $\mu \tilde{\tau} \iota \varsigma$, da astúcia, de Helena.

\section{Conchusão}

Como tentamos demonstrar até aqui, Helena ocupa nos poemas homéricos um status privilegiado em relação às demais mulheres descritas pelo poeta. Utilizamos quatro eixos de análise (técnico-poético, espacial, ético e discursivo) para evidenciar de que maneira a personagem subverteu as relações de gênero. Mais do que justificar tal destaque pela sua genealogia - filha de Zeus, como tantas vezes nos lembra Homero -, podemos conjecturar que, se em alguma medida há uma representação da realidade no que diz respeito a hábitos e costumes de época na Iliada e na Odisseia, a figura de Helena pode contribuir para alargar o nosso entendimento sobre as relaçóes de gênero no século VIII. 
Defendemos que esse novo quadro teórico oferecido pelas discussões de gênero contribuiu para o alargamento dos domínios da pesquisa, para a inserção da história sobre as mulheres na história global (BERNARD, 2003, p. 4). E a força de ação feminina também é ressaltada por Helena como um legado para as futuras geraçóes. Ela diz a Heitor em um exercício claro de metalinguagem e consciência poética, "sobre nós fez Zeus abater um destino doloroso, para que no futuro / sejamos tema de canto para homens ainda por nascer" (HOMERO, Ilíada, VI, vv. 357-358).

\begin{abstract}
This article aims to analyze the character of Helen in Iliad and Odyssey from gender perspective. To achieve our goal, we have adopted four research axis - technical-poetic, spatial, ethic and discursive - in order to investigate how Helen subverts the gender relations in homeric epic. We argue that Helen's speeches and acts reveal her special status in those poems, what can make us reflect about the spheres of action and participation of women in Homer's time.

Keywords: Archaic Greece, Homer, Helen, Gender.
\end{abstract}

\title{
REFERÊNCIAS
}

\section{Documentação escrita}

ARISTÓTELES. Poética. Trad. Antônio Mattoso e Antônio Queirós Campos. Belo Horizonte: Autêntica, 2018.

EURÍPIDES. Hécuba. Trad. Maria do Céu Fialho e José Luís Coelho. In: SILVA, M.F.S. (Coord.). Eurípides: Tragédias II. Lisboa: Imprensa Nacional-Casa da Moeda, 2010 .

HERÓDOTO. História. Trad. Mário G. Kury. Brasília: Ed. UnB, 1988.

HESÍODO. Teogonia: a origem dos deuses. Trad. deJaaTorrano. São Paulo: Iluminuras, 1991.

HOMERO.Ilíada. Trad. F. Lourenço. São Paulo: Cia. das Letras, 2013. . Odisseia. Trad. F. Lourenço. São Paulo: Cia. das Letras, 2011.

TUCÍDIDES. História da Guerra do Peloponeso. Trad. Anna Lia Amaral de A. Prado. São Paulo: Martins Fontes, 2008.

XENOFONTE. Econômico. Trad. Anna Lia A. de Almeida Prado. São Paulo: Martins Fontes, 1999.

\section{Bibliografia}

BERNARD, Nadine. Femmes et societé dans la Grèce classique. Paris: Armand Colin, 2003.

BERGREN, Ann. Weaving Truth: Essays on Language and the Female in Greek Thought. Washington: Center for Hellenic Studies, 2008. 
BESPALOFF, Rachel. Helen. In: STEINER, George; FAGLES, Robert (Ed.). Homer: A Collection of Critical Essays. Englewood Cliffs: Prentice-Hall, 1965.

BETTINI, Maurizzo; BRILLANTE, Carlo. El mito de Helena: Imágenes y relatos de Grecia a nuestros dias. Madrid: Akal, 2008.

BOEHRINGER, Sandra; CUCHET, Violaine Sebillotte. (Dir.). Hommes et femmes dans l'Antiquité grecque et romaine. Malakoff: Armand Colin, 2017.

Bourdieu, Pierre. A dominação masculina. Rio de Janeiro: Bertrand Brasil, 2002.

CALAME, Claude. Poétiques des mythes dans la Grèce antique. Paris: Hachette, 2000 .

. Hélène, cause de la guerre de Troie. In: BOEHRINGER, S.; CUCHET, V.S. (Dir.). Hommes et femmes dans l'Antiquité grecque et romaine. Malakoff: Armand Colin, 2017.

CUNLIFFE, John R. A lexicon of the Homeric dialect. Norman: University of Oklahoma Press, 1963.

DAVIDSON, James. Bodymaps: Sexing Space and Zoning Gender in Ancient Athens. In: FOXHALL, Lin; NEHER, Gabriele. Gender and the city before Modernity. Oxford: Wiley-Blackwell, 2013, p. 107-24.

DOYLE, Andrea. "Unhappy even after?" The Problem of Helen in Odyssey IV. Akroterion, vol. 55, 2010, p. 1-18.

FASANO, Graciela C. Zecchin. Apuntes sobre la visión homérica de lo femenino. In: LESSA, F.; FASANO, G. C. Z. (Org.). Literatura e sociedade na Grécia Antiga. Rio de Janeiro: Mauad X, 2018, p. 11-30.

FELSON, Nancy; SLATKIN, Laura M.; Gender in Homeric Epic. In: FOWLER, R. (ed.). The Cambridge Companion to Homer. Cambridge: Cambridge University Press, 2006.

FOXHALL, Lin. Studying Gender in Classical Antiquity. Cambridge: Cambridge University Press, 2013.

KARANIKA, Andromache. Voices at Work: Women, Performance and Labor in Ancient Greece. Baltimore: John Hopkins University Press, 2014.

KATZ, Marylin A. The Divided World of Iliad VI. Women's Studies, vol. 8, n. 1-2, 1981, p. 21-46.

KENAAN, VeredLev.Silent Images: The Role of Mythological Weaver in Ancient Criticismo. In: JÄKEL, Siegfried; TIMONEN, Asko. The Language of Silence. Vol. 1. Turku: Turun Yliopisto, 2001, p. 182-196.

KIRK, Geoffrey etalii. The Iliad: a commentary. 6 vols. Cambridge: Cambridge University Press, 1985-1993.

LESSA, Fábio de Souza Mulheres de Atenas: Mélissa do gineceu à agorá. Rio de Janeiro: Mauad X, 2010.

LORAUX, Nicole. The Experiences of Tiresias: The Feminine and the Greek Man. Princeton: Princeton University Press, 1995.

LOURENÇO, Frederico. Helena na epopeia homérica. In: BANUULS, J.V. etalli (Ed.). $\mathrm{O}$ mito de Helena de Troia à actualidade. Coimbra: Universidade de Coimbra, 2007, p. 47-53.

MALTA, André. Metapoesia e a Helena de Homero. Nuntius Antiquus, Belo Horizonte, v. 12, n. 1, p. 13-25, 2016. 
MATOS, Maria Izilda Santos de. Gênero: categoria/perspectivas e constituição do campo historiográfico. In: TAMANINI, Marlene et alli. Teorias e Políticas do Gênero na Contemporaneidade. Curitiba: Ed. UFPR, 2017, p. 39-63.

MELLO, Maria M. Pimentel de. A Mulher em Homero. Phoînix, Rio de Janeiro, n. 2, p. 215-228, 1996.

MINCHIN, Elizabeth. Homeric Voices: Discourse, Memory, Gender. Oxford: Oxford University Press, 2007.

POMEROY. Sarah. Diosas, rameras, esposas y esclavas: Mujeres em la Antigüedad clásica. Madrid: Akal, 1999.

ROISMAN, Hanna M. Helen in the "Iliad" "Causa Belli" and Victim of War: From Silent Weaver to Public Speaker. The American Journal of Philology, Vol. 127, No. 1, 2006, p. 1-36.

ROMILLY, Jacqueline de. Homero: introdução aos poemas homéricos. Lisboa: Edições 70, 2001.

SAIS, Lilian A. Mulheres de Homero: o caso das esposas da Odisseia. 2016. Tese (Doutorado em Letras Clássicas) - Departamento de Letras Clássicas e Vernáculas, Universidade de São Paulo, São Paulo.

SEIJO, Francisca Gómez. Responsabilidad y ambiguëdad de Helena en la épica homérica. Humanitas, Coimbra, v. 69,2017,p. 9-45.

SCOTT, Joan. The problem of invisibility. In: KLEINBERG, Jay. Retrieving Women's History: Changing Perceptions of the Role of Women in Politics and Society. Paris: UNESCO/Berg, 1989, p. 5-29.

- Prefácio a Gender and Politics of History. Cadernos Pagu: desacordos, desamores e diferenças, Campinas, v. 3, 1994, p. 11-27.

. Gênero: uma categoria útil de análise histórica. Educação $\&$ Realidade, v. 20, n.2, 1995, p. 71-99.

VIDAL-NAQUET, Pierre. O mundo de Homero. São Paulo: Cia. das Letras, 2002.

WEST, Martil L. Greek Epic Fragments: From the Seventh to the Fifth Centuries BC. London; Cambridge: Harvard University Press, 2003.

. The making of the Iliad: disquisition and analytical commentary. Oxford:

Oxford University Press, 2011. 